\title{
A naturalização da escola enquanto tecnologia
}

\section{Resumo}

O artigo explora o problema da naturalização da escola no contexto da crise de sentido e legitimidade da tecnologia da escola. Há certo tempo que a instituição escolar moderna é alvo de análises, as quais, de um modo geral, não se concentram no instrumento em si mesmo, na própria estrutura da tecnologia da escola. É possível pensar a escola para além de um contexto socioeconômico específico? Neste texto, parte-se do pressuposto de que é possível focar na análise da escola enquanto tecnologia, no próprio instrumento, e propõe como meta, em fase exploratória, a noção de ambivalência da tecnologia como alternativa para superar a naturalização da tecnologia da escola e, consequentemente, a crise de sentido e legitimidade da escola enquanto tecnologia e das formas de pensá-la.

Palavras-chave: escola; tecnologia; naturalização; ambivalência.

\begin{abstract}
The article explores the problem of school naturalization in the context of the crisis of meaning and legitimacy of school as technology. For some time that modern educational institution is the subject of several analyzes and critical approaches, which, generally, do not focus on the instrument itself, namely in school as technology. In this text, it is proposed, in initial phase, the notion of ambivalence of technology as an alternative to overcome the naturalization of school as technology and hence the crisis of meaning and legitimacy of school as technology.
\end{abstract}

Keywords: school; technology; naturalization; ambivalence.

Filosofia e Educação [rfe] - volume 7, número 3 - Campinas, SP

Outubro de 2015-Janeiro de 2016 - ISSN 1984-9605 - p. 27-56 
La contraposición o disyuntiva que allí se maneja entre 'engaño' o 'derecho social' se me antoja de una pobre y escasa entidad. La escuela es un bien y un mal al mismo tempo ¿Imagina alguien que yo, o cualquier bípedo pensante, renuncie al derecho a la atención sanitaria, que deje de reclamar mi derecho a la medicina gratuita, que suspenda una operación de próstata, en razón de considerar la política sanitaria y la tecnología médica como instrumentos de dominación social? No es esto o aquello. Es esto ('engaño') y aquello ('derecho social') al mismo tiempo. Y ahí, claro, si yo exagero (que lo hago premeditadamente) cuando enfatizo en 'esto', mi amigo hace lo propio cuando pone el acento en 'aquello'.

Raimundo Cuesta, Paradojas de la escuela en la era del capitalismo: carta a mis queridos críticos

\section{Introdução}

crítica da instituição escolar não é recente. Desde quando se
consolidou, com base no pensamento de Comenius, a
compreensão da escola enquanto tecnologia fundamental para a efetivação do pedagógico na sociedade moderna que há, em diferentes vertentes, análises que focam limites e potencialidades dessa instituição (Canário, 2006, 2005, 2008; Cuesta, 2004, 2006, 2011, 2015; Illich, 2006; Pineau, 2001, 2015; Monteiro, 2013; Stuchul, 1999). De diferentes ângulos e com suporte em teorias diversas, o movimento de crítica da escola, especialmente nos últimos tempos, incorpora, em espiral crescente, um número maior de interessados. Alguns encontram suporte na sociologia da educação, outros na economia, para não mencionar os aportes advindos da psicologia da educação e demais áreas que confluem com o pedagógico (Canário, 2006; Cuesta, 2004, 2006, 2011). 
A esse respeito, talvez não seja sem sentido afirmar que as diversas análises da instituição escolar podem ser categorizadas com base em dois eixos. O primeiro compreende que a escola ainda não efetivou seu potencial na sociedade moderna e, por isso, é necessário buscar o aprimoramento de novas formas de efetivação da instituição escolar na sociedade moderna. $\mathrm{O}$ segundo eixo de análise envolve aqueles que compreendem que o projeto escolar moderno atingiu sua plenitude, e que o cerne do problema não reside em melhorar a escola, mas antes colocar em questão o sentido e a legitimidade dela enquanto tecnologia hegemônica de efetivação do educativo nas modernas sociedades (Canário, 2008; Cuesta, 2006, 2011). Nesse segundo foco de análise a questão que se impõe é, em certo sentido, saber qual o preço a se pagar por assumirmos o escolar como paradigma para se pensar o educativo nas suas diferentes formas e dimensões. Mesmo ciente dos limites dessa categorização, acreditamos que ela possui a capacidade de explicitação do cerne do problema.

Assim, é nesse segundo eixo que inserimos a preocupação exposta neste artigo. Nele, procuramos inquirir a escola enquanto tecnologia hegemônica do educativo na nossa sociedade, especialmente a partir da caracterização do problema da naturalização da forma escolar. Esperamos, dessa forma, no esforço de participar desse debate, contribuir com a emergência de elementos teóricos que permitam problematizar a compreensão, por demais difundida no atual contexto, de que a escola é a solução de todos os problemas sociais, econômicos e políticos, sempre atrelada a certo discurso salvífico de uma tecnologia como fonte de redenção e felicidade. Importante assinalar, ainda, que a preocupação neste texto é com o instrumento em si, com a análise da tecnologia. Isso quer dizer que esse tipo de análise, neste texto em caráter preliminar, procura pensar a escola para além de um contexto socioeconômico específico. Ou 
seja, as reflexões e análises propostas neste artigo se articulam em termos de análises que possam focar a própria estrutura da tecnologia escola.

De alguma forma, propomos pensar a escola enquanto tecnologia, bem como o sentido e a legitimidade dessa instituição enquanto paradigma para as práticas pedagógicas modernas. Assim, esperamos fazer valer também a importância da outra face da moeda em que, mais do que visualizar a escola como solução de todos os problemas, também ela é parte dos problemas e precisa, nessa condição, ser objeto de análise e crítica. É necessário repensar a escola e o futuro da educação posto em termos de lógica escolar (Canário, 2008; Cuesta, 2006, 2011). Assim, neste artigo, ao caracterizarmos o problema da naturalização da forma escolar na modernidade, procuramos no texto A ambivalência das técnicas de Jacques Ellul algumas pistas que nos permitam delinear a escola enquanto tecnologia ambivalente como alternativa ao problema da naturalização da forma escolar, com a consequente crise de sentido e legitimidade dessa instituição. No que concerne a sua estrutura, basicamente, o texto está composto de duas partes: a primeira, em que caracterizamos o problema da naturalização da escola; a segunda, quando ressaltamos a noção de ambivalência das técnicas proposta por Ellul. Nas considerações finais, procuramos elencar o potencial do conceito do autor para repensar o problema da naturalização da escola e, consequentemente, a crise de sentido e legitimidade dessa tecnologia.

Ressaltamos, por fim, que a construção deste texto é tributária da leitura do movimento de autores que, há certo tempo, dedica-se à análise $\mathrm{e}$ crítica da escola. Embora com diferentes nuances, focos e enfoques diversos, teorias e metodologias nem sempre aproximadas, pensamos ser possível sintetizar esse movimento naquilo que Cuesta denomina da crítica da escola na sociedade capitalista. É nesse contexto que dialogamos com 
textos de teóricos como Rui Canário (2006; 2005; 2008), Raimundo Cuesta (2004; 2006; 2011; 2015), Ivan Illich (2006), Pablo Pineau (2001; 2015), apenas para mencionar alguns.

\section{O problema da naturalização da escola}

O fato é que a escola assume na nossa sociedade a condição das grandes obviedades (Canário, 2006, 2005, 2008; Cuesta, 2004, 2006, 2011, 2015; Illich, 2006; Pineau, 2001, 2015). Ela - ao incorporar a característica de um desses óbvios, que se apresentam como um dado natural da realidade e não podem ser objeto de crítica - parece incorporar a condição de verdade eterna, sem historicidade, sem contradições, sem vínculos com determinados contextos. Esse novo status não parece apenas tornar a escola imune às críticas, mas também observamos que vários fatos sociais e econômicos tendem a ser analisados, em muitos momentos, em função dos propalados triunfos ou fracassos da escola (Canário, 2006; Cuesta, 2006; Pineau, 2001).

Isso é que exploramos neste texto como naturalização da escola. Como escreve Cuesta (2004, p. 1), "la masiva asistencia obligatoria a la escuela pertenece al género de obviedades que hoy no es preciso explicar a nadie: son porque están". Na mesma perspectiva, acrescenta o autor (2004, p. 1), "de ahí que la admitida bondad de la obligatoriedad y universalidad escolar posea la fuerza inexpugnable de los fenómenos sociales que se propagan hasta hacerse verdades eternas más allá de las circunstancias específicas en que nacieron".

No entanto, a escola está impregnada da lógica e dos valores de uma determinada sociedade. Ela guarda compromissos com determinado modelo de Estado e, além disso, contém elementos invariáveis, os quais, em 
diferentes contextos, se mantêm os mesmos. Mudam as condições, os contextos, mas a tecnologia da escola permanece intacta (Illich, 2006).

$\mathrm{O}$ protagonismo e o status adquirido pela escola nas atuais sociedades parecem assumir dimensão tal que a escola se apresenta, também, como paradigma para outras dimensões sociais (Canário, 2008). No caso específico da educação, é comum constatarmos experiências pedagógicas relativas às modalidades não-formais e informais serem reconfiguradas em conformidade com a lógica escolar (Canário, 2006; 2005; 2008). Em vez da lógica escolar ser desafiada, questionada e problematizada pelas experiências educativas não formais e informais, as evidências apontam, justamente, no caminho inverso. Com isso, os limites do escolar são ampliados e propalados para outros campos (Illich, 2006).

Essa realidade omnipresente e naturalizada, "como se tratasse de fenômeno biologicamente propagado, com origem eventualmente desconhecida" (Limna, 2005, p. 19), é, muitas vezes, objeto de crença quase mitológica tanto à direita quanto à esquerda. É por isso que se pode compreender por que autores que se voltaram de forma mais detida à crítica da escola, tais como Ivan Illich, passaram a ser criticados pelos capitalistas e pelos socialistas. Mitcham (2002), ao comentar as críticas da esquerda ao pensamento de Ivan Illich, identifica que a escola sempre foi uma das vacas sagradas da denominada esquerda progressista na modernidade. Em suma, embora na sua origem a escola seja elitista e, de uma forma ou de outra, está eivada dos compromissos e dos valores da sociedade de consumo, da sociedade capitalista, ela se torna um dos mitos não só dos capitalistas, mas também dos socialistas. A tecnologia da escola, nesse caso, é apresentada como se tivesse sido a vitória do melhor caminho, the best way.

A escola assume, assim, as aparências de mito. Parece que para liberais e socialistas mais escolas correspondem à modernidade. Nesse caso, 
ser moderno seria sinônimo de terra prometida, de felicidade a ser alcançada por todos. A crença, cada vez mais difundida, de escola como tábua de salvação da humanidade não só se encontra amplamente fortalecida como reúne sempre mais novos adeptos. Sobre isso, talvez seja conveniente lembrar com Illich (2006) - e por que não também em referência ao pensamento de Marcuse (1973) - que o próprio mito desenvolve a sua mitologia. De acordo com Illich (2006), alguns poucos anos na escola são suficientes para o fortalecimento da noção de que aprender é sinônimo de frequentar a escola, de que o futuro depende dos anos que se passa na escola. Muitas pessoas que poderiam se sentir capazes de aprender várias coisas interessantes tendem a se considerar impossibilitadas pela não frequência à escola. Dessa forma, a própria escola interioriza e desenvolve o mito da escola enquanto terra prometida.

Subjacente a essa crença da escola enquanto terra prometida, talvez esteja a ideia de neutralidade para a tecnologia. No entanto, análises sobre o desenvolvimento de algumas tecnologias demonstram que aquilo que procura se apresentar como the best way esconde os vários caminhos possíveis (Feenberg, 2001). Por exemplo, tendemos a visualizar o atual modelo hegemônico de bicicleta - com duas rodas iguais - como se fosse a vitória técnica do melhor modelo. Como Feenberg (2001) escreve, no processo de desenvolvimento e consolidação da tecnologia da bicicleta, houve disputas entre os diferentes modelos e, em função de um conjunto de escolhas, o modelo de duas rodas iguais se consolidou como modelo hegemônico. Assim, cada tecnologia, nesse caso, representa um conjunto de escolhas e valores, em detrimento de outras possibilidades. De acordo com esse filósofo da tecnologia, é profundo equívoco pensar em termos de vitória de um modelo técnico em nome da eficiência e da eficácia. 
No caso específico da escola, Cuesta (2006), em argumentação que se aproxima da análise de Feenberg (2001) sobre a tecnologia em geral, defende que a escola apresenta a característica dos vencedores. Sobre isso, escreve o autor: "la genealogía de cualquier valor e institución de nuestro tempo ostenta la huella terrible de los vencedores y aloja un cúmulo de sufrimientos, olvidos y servidumbres que no podemos ignorar" (CUESTA, 2006, p. 55).

Essa situação em que a escola é visualizada como tecnologia hegemônica da educação, supostamente neutra - quando não são poucos que encontram nela o ídolo da terra prometida -, fruto de algum processo biológico, dificulta o repensar a escola (Canário, 2006, 2005, 2008; Cuesta, 2004, 2006). É nesse sentido que há um conjunto de análises, tais como a de Ivan Illich (2006), que demarcam que se desejamos uma sociedade mais humana é necessário destruir esse ídolo. Não é possível conformar o futuro nos limites postos pela tecnologia atual.

Ora, quando nos voltamos para a análise mais detida da escola enquanto tecnologia hegemônica da educação na sociedade atual, vemos que talvez estejamos diante daquilo que muitos denominam, em relação a determinadas tecnologias, de black box. Ou seja, a escola é uma tecnologia que precisa não só ser criticada, analisada, mas aberta de forma a que se possa conformar novas possibilidades de futuros que não são incorporadas nos estreitos limites da lógica escolar. Nesse sentido somos levados a questionar, com apoio na filósofa Olga Pombo: “que pensar, perante este estado de coisas, este verdadeiro emaranhado de equívocos, deslizamentos lógicos e falhas conceptuais em que está enredada a instituição escolar? E, mais grave ainda, que fazer?” (Pombo, 2015, p. 26).

Não se trata necessariamente de pensar a possibilidade de uma sociedade sem escolas, mas de observação mais detida sobre aquilo que 
conforma essa black box. Isso, por exemplo, ajuda a ter maior clareza da dimensão política da tecnologia da escola e, dessa forma, ao mostrar também sua dimensão histórica, afasta-se de visões fragmentadas e atomizadas sobre a escola (Canário, 2006, 2005, 2008; Cuesta, 2004, 2006, 2011, 2015; Illich, 2006; Pineau, 2001, 2015). Isso poderá, por exemplo, apontar elementos sobre o projeto de poder e de controle que estão introjetados no próprio instrumento, deixando pouca margem, por exemplo, para se pensar em neutralidade para a tecnologia da escola.

Convém lembrar, nesse contexto, que os esforços em torno de movimentos tais como home schooling representam muito pouco no universo mais amplo de fluência às escolas obrigatórias. De fato, como bem identifica Cuesta (2015), não há como desconhecer o fato de que é cada vez mais comum observar pais que desejam educar os seus filhos em casa. Até mesmo quando a legislação do país não permite alternativas, é usual constatar movimentos de pais que recorrem aos tribunais no esforço de construir alternativas à escola. Porém a dimensão disso é reduzida. Nas palavras de Cuesta (2004, p. 1):

Los esporádicos movimientos actuales contra la irrefrenable tendencia a la escolarización obligatoria, como el home schooling en USA, no representan más que una tormenta en un vaso de agua, que no altera el océano de países, estados, organismos, opiniones públicas, sindicatos, partidos, iglesias, etc. defensores, a mayor gloria de Dios y los hombres (y mujeres), de la máxima extensión de la escuela obligatoria.

Em síntese, embora haja movimentos de reinvenção das escolas e, ao mesmo tempo, não sejam recentes as críticas à escola, ainda há duas crenças que estão bem consolidadas em relação a essa tecnologia (CANÁRIO, 2008;

Filosofia e Educação [rfe] - volume 7, número 3 - Campinas, SP

Outubro de 2015-Janeiro de 2016 - ISSN 1984-9605 - p. 27-56 
Cuesta, 2006, 2011). Primeiro, a escola como sinônimo de salvação, de grande bondade para a humanidade. Segundo, a de que a escola necessita ser reformada nos moldes da lógica escolar, para que, efetivamente, venha a atingir os seus objetivos. De certo modo, o discurso geral, especialmente no âmbito político, é de que as escolas necessitam ser reformadas. Os que se posicionam nessa direção defendem que a escola ainda não mostrou o seu potencial. Por outro lado, conforme mencionamos, outras análises estabelecem uma relação com a escola que, para além de buscar mais eficácia da lógica escolar na sociedade atual, procuram estabelecer limites para os rumos que estão postos para a escola enquanto tecnologia hegemônica da educação (Canário, 2006, 2005, 2008; Cuesta, 2004, 2006, 2011, 2015; Illich, 2006; Pineau, 2001, 2015). Essas análises, mais do que denunciar a outra face da moeda, a função legitimadora e excludente da instituição escolar, culminam mesmo por colocar em questão o sentido e a natureza dessa tecnologia na nossa sociedade. Contudo, o universo daqueles que não se dão por satisfeitos na conformação do futuro nos moldes postos pela lógica escolar é ainda por demais restrito. Há poucos trabalhos que focam a análise do instrumento em si mesmo, a escola enquanto tecnologia.

Sem dúvida, o questionamento da escola, enquanto tecnologia hegemônica da educação na nossa sociedade, implica certo inconveniente (Illich, 2006; Cuesta, 2011). Embora seja uma tarefa do ser humano pôr em questão aquilo que é apresentado como dado, como eterno, a maior inquietação em problematizar a escola reside no fato de que todos passamos por ela e todos tendemos a vê-la como objeto de felicidade. Ora, como então colocar em questão aquilo que é o objeto de salvação? Como visualizar erros, equívocos, dominação, onde quase todos veem apenas felicidade? (Cuesta, 2004, 2006, 2011, 2015). É nesse sentido que compreendemos o potencial do pensamento de Jacques Ellul, enquanto sociólogo e filósofo da 
tecnologia, no sentido de aduzir elementos que ajudem a pensar esse problema de naturalização da forma escolar e, consequentemente, essa crise de sentido e legitimidade da escola enquanto tecnologia hegemônica do educativo.

\section{A ambivalência das técnicas e da tecnologia da escola}

Neste texto, ao focarmos na naturalização da tecnologia da escola, propomos, em análise preliminar e inicial, explorar a noção de ambivalência da tecnologia proposta por Ellul como alternativa para pensar essa naturalização, bem como a própria crise de sentido e legitimidade da escola enquanto tecnologia hegemônica do educativo. De alguma forma, também é nossa intenção levantar questões em torno da escola as quais possam, inclusive, demonstrar o potencial da sociologia da tecnologia e do pensamento de Jacques Ellul (1968; 2009) para repensar a tecnologia da escola e de nossa relação com a mesma.

Em outras palavras, de forma exploratória, na sequência abordamos um aspecto das tecnologias e como isso pode rebater sobre a tecnologia da escola, a questão da ambivalência das técnicas. Devido aos objetivos propostos para este artigo, bem como ao escopo que nos propomos e - por que não mencionar? - a dificuldade com que historicamente os teóricos encontram quando se concentram na questão da ambivalência da tecnologia, trazemos alguns elementos teóricos sobre esse problema a partir da releitura do texto A ambivalência das técnicas do teólogo e sociólogo da tecnologia Jacques Ellul. Pensar a escola como uma tecnologia ambivalente pode contribuir para a superação da crise de sentido e de legitimidade que aflige a escola.

Dessa releitura do texto do teólogo e sociólogo francês, talvez possamos colher elementos para pensarmos questões do tipo: o que seria 
pensar a tecnologia da escola enquanto tecnologia ambivalente? Ou ainda, quais as consequências da aplicação do conceito de ambivalência da tecnologia proposto pelo autor para a compreensão da tecnologia da escola? Em que medida as reflexões da sociologia da tecnologia de Jacques Ellul podem contribuir para se pensar a crise da tecnologia da escola? Ao fazermos a releitura desse texto de Jacques Ellul, cremos que é possível pensar não somente o problema da naturalização da tecnologia da escola, mas também a escola enquanto tecnologia hegemônica do educativo na modernidade.

Finalmente, breve comentário sobre o artigo que será tomado como fio de Ariadne na sequência. Denominado de $A$ ambivalência das técnicas, ele está inserido no livro Le bluff technologique, com publicação de 1988. Tal artigo dialoga com uma versão seminal de 1965, publicada na Revue Administrative, vol. 18, cujo título Réflexions sur l'ambivalence du progrès technique não permite muitas dúvidas sobre o cerne do problema em análise. Nele, Jacques Ellul se volta para o problema da ambivalência das técnicas, explorando desde as incompreensões em relação ao conceito até os aspectos centrais da ambivalência. Por questões afeitas ao escopo deste artigo e, enquanto releitura, não propomos, por ora, ampliar o diálogo com outros textos de Ellul, nem com outras reflexões de filósofos e sociólogos da tecnologia.

Não é necessário ser estudioso da tecnologia para colher a impressão hegemônica de que para os políticos e para o cidadão comum a noção prevalente é de neutralidade das técnicas. Nessa perspectiva, a possibilidade de ambivalência das técnicas se restringe a pensar que a técnica pode ser boa ou má, conforme o uso que lhe seja feito. No caso da tecnologia da escola, não é incomum identificarmos também em âmbito acadêmico profissionais que compreendem que os efeitos da escola dependem, 
exclusivamente, do uso que lhe é feito. Sobre essa compreensão usual em relação à ambivalência das técnicas como neutras, as palavras de Ellul podem nos ajudar a delimitar melhor os termos: "com uma faca, podemos descascar uma maçã ou matar o vizinho" (Ellul, 2009, p. 260). No entanto, o próprio sociólogo contrapõe (Ellul, 2009, p. 260): “tentei mostrar em outros trabalhos que esta comparação é absurda e que a técnica carrega consequências em si, independentemente do seu uso".

Não queremos, em conjunto com Ellul (2009), advogar que a questão do uso é irrelevante no processo de análise das técnicas. Aquilo que pretendemos denotar é o fato de que esse olhar não abarca a complexidade do problema, visto que, como será assinalado mais adiante com base na releitura de Ellul (2009), não é possível colocar a questão dos efeitos apenas no uso que é feito de determinada tecnologia. A não complexidade da abordagem da neutralidade fica patente quando se procura identificar o pressuposto da mesma, qual seja, o da neutralidade das técnicas. Contudo, não são poucos os estudos em sociologia da tecnologia e filosofia da tecnologia a demonstrarem a fragilidade dos argumentos em favor da tese da neutralidade das técnicas. A não neutralidade implica, por outro lado, perceber que é “inerente a ela [técnica] certo número de consequências positivas ou negativas, independentemente do seu uso" (Ellul, 2009, p. 260).

Nesse caso, somos convidados a reconhecer que as potencialidades inerentes da técnica são mais importantes do que as intencionalidades daqueles que se devotam ao uso. Sem dúvida que é possível minimizar certos aspectos negativos ou até mesmo - como identifica Ellul (2009) redirecioná-los por determinados períodos para as dimensões positivas, porém, mais cedo ou mais tarde, as potencialidades inerentes emergem e passam a ser exploradas. "Um exemplo simplista e bem conhecido é a pólvora. Os chineses a utilizaram unicamente em fogos de artifício, mas ela 
continha potencialidades, por nós conhecidas, que não poderiam ser negligenciadas por muito tempo" (Ellul, 2009, p. 260).

Além disso, não estamos fora do contexto técnico (Ellul, 2009). Há limites em pensar e analisar a situação técnica, uma vez que estamos inseridos nesse contexto. Isso demarca significativa complexidade e disputas, em função da própria aceleração das transformações a que somos obrigados a assistir. Além disso,

a transformação é global (concerne ao conjunto da humanidade, todos os aspectos da sociedade e da civilização) e pessoal (modificando as nossas ideias, os nossos estilos de vida e os nossos comportamentos). E não podemos deixar de nos perguntar no que nos tornaremos neste processo de mudanças radicais. (ELLUL, 2009, p.261)

Estamos, portanto, frente a um contexto e uma situação que talvez tenhamos dificuldades em delinear quais serão os rumos, bem como em responder à própria questão sobre o que nos tornaremos.

Mesmo ciente dessas limitações, Ellul nos apresenta uma aproximação ao conceito de ambivalência das técnicas que compreendemos importante para pensar a tecnologia da escola. Escreve o autor (2009, p. 262): “eu entendo por ambivalência que o desenvolvimento da técnica não é bom, nem mau, nem neutro, mas que é uma mistura complexa de elementos positivos e negativos, 'bons' e 'maus', se quisermos utilizar um vocabulário moral". Nessa perspectiva, os elementos positivos e negativos estão implicados e não nos é possível - apenas por um determinado uso - separálos, de forma a prevalecer os aspectos positivos das técnicas.

Os objetos técnicos se comunicam com quem os utiliza e, nesse caso, a questão não é tanto o que fazemos com eles, mas o que eles fazem 
conosco, o que eles nos comunicam durante o processo de uso (Ellul, 2009). Caso reconheçamos, em conjunto com Ellul (2009), que há um processo de "adaptação psicológica" aos meios técnicos, temos que reconhecer que somos orientados pelas condições técnicas. Nas palavras do teólogo e sociólogo da tecnologia: "assim, perdemos a nossa independência: não somos um sujeito em meio a objetos sobre os quais poderíamos decidir livremente nosso comportamento: estamos estreitamente implicados por este universo técnico, condicionados por ele" (Ellul, 2009, p. 262).

Essa primeira aproximação ao conceito de ambivalência da tecnologia não nos fornece, ainda, muitos elementos teóricos que nos permitam se distanciar daquela posição delineada antes que tem como pressuposto a tese da neutralidade dos objetos técnicos. Desse modo, propomos buscar melhor delimitação e caracterização da ambivalência dos objetos técnicos ainda no próprio Jacques Ellul. Continuamos, portanto, a seguir o autor, tanto nas distinções que ele procede entre as noções de ambiguidade e efeito perverso em relação à ambivalência das técnicas, quanto nas quatro fórmulas - com os respectivos exemplos - que o autor apresenta para delimitar sua compreensão de ambivalência das técnicas.

Se de um lado a ambivalência implica em Ellul (2009) "duas orientações precisas", porém com valores opostos no mesmo objeto, o termo ambiguidade remete a algo impreciso, confuso e indefinido (Ellul, 2009). Nestes termos, o autor demarca: “ora, a técnica não é nem confusa nem indeterminada, mas é perfeitamente certa e não parece nada equívoca" (Ellul, 2009, p. 264). De outra parte, temos a tão utilizada noção de efeitos perversos, cujo significado e sentido parecem confundir Ellul (2009), na medida em que remete somente à questão do uso - nesse caso o "uso perverso" -, fazendo eclodir, apenas em outros termos, os "efeitos normais" e os "efeitos perversos". Desse modo, na utilização dessas duas noções nos 
afastamos daquilo que consiste o cerne da ambivalência das técnicas: “[...] precisamos entender que o 'bem e o mal', os efeitos bons e maus estão intrinsecamente ligados na constituição do universo técnico e em toda técnica" (Ellul, 2009, p. 264).

A distinção proposta antes pelo autor entre o conceito de ambivalência das técnicas para com ambiguidade e efeitos perversos nos ajuda melhor delimitar a ambivalência das técnicas. Além disso, consideramos importante para a construção e objetivos deste artigo, abordarmos as quatro fórmulas que o autor nos fornece para caracterizar melhor aquilo que denomina de ambivalência das técnicas. Após a apresentação dessas posições, nas considerações finais deste texto, empreendemos esforço exploratório e inicial em retirar elementos teóricos para pensarmos o problema da naturalização da tecnologia da escola. Em relação às fórmulas, o autor delineia as seguintes: a) "todo progresso técnico se paga"; b) "a cada etapa, o progresso técnico levanta mais problemas (e maiores) que aqueles que resolve"; c) "os efeitos nefastos do progresso técnico são inseparáveis dos efeitos benéficos"; d) "todo progresso técnico compreende um grande número de efeitos imprevisíveis".

A primeira fórmula delineada por Ellul (2009) pode ser sistematizada nos seguintes termos "é evidente que a técnica aporta valores consideráveis, indiscutíveis. Mas ela destrói outros dos quais é impossível dizer se são mais ou menos importantes que os anteriores" (Ellul, 2009, p. 272). Essa citação delimita o pressuposto de que "todo progresso técnico se paga". E, nesse sentido, destacamos a ênfase que o autor pontua não só no fato da existência de substantivas criações técnicas, mas que essas criações implicam necessariamente "determinado preço".

Não é fácil, sem dúvida, estabelecer os termos da relação entre criação e destruição, para utilizar os termos de Ellul (2009), visto que são 
fenômenos que lidam com medidas e naturezas diferenciadas. Não é algo que se coloque, como assinala o próprio autor, nas condições de valor-valor. Isso, contudo, não elimina a questão fundamental, "há sempre um preço a se pagar". Esse preço, inclusive, nem sempre está posto em termos mais restritos, pois - como demarca o próprio Ellul (2009) -, esse preço pode ser cobrado em âmbito global.

A questão posta nesses moldes implica compreender que a presença de determinada técnica em uma área pode ter consequências - o preço a se pagar - em outro campo, ou até mesmo em outro momento. Finalmente, convém assinalar que "por preço a pagar", o teólogo e sociólogo da tecnologia não está, necessariamente, se referindo a compreensão usual restrita a esforços intelectuais - demandados pelo empreendimento - ou mesmo injeção de recursos - necessários na concepção, invenção e operação de determinadas tecnologias. A questão se coloca em termos mais complexos do que os identificados nesses dois domínios (Ellul, 2009).

Podemos, então, abordar a segunda fórmula apresentada por Ellul (2009) acerca da ambivalência das técnicas. Essa segunda fórmula, nas palavras de Ellul (2009), é um fato evidente, qual seja, “o progresso técnico suscita problemas mais difíceis do que aqueles que ele resolve”. Ao delinear para o leitor essa fórmula, o autor de A técnica e do desafio do Século encontra em questão posta por Elgozy o móvel fundamental para esclarecêla. O suporte às reflexões de Elgozy traz, ao mesmo tempo, certa dose de ironia, na medida em que ele não pode ser considerado um dos críticos da técnica, visto que a visão comumente divulgada é de que ele pode, tranquilamente, ser inserido entre os defensores da tecnologia (Ellul, 2009).

A questão posta por Elgozy, então, envolve saber se a informática “apresentaria mais problemas que aqueles que poderia resolver". Conforme a apresentação de Ellul (2009), Elgozy questiona, ainda, se seria oportuno 
substituir o computador por um "sistema de mecanografia menos presunçoso". Essa provocação de Elgozy, sem dúvida, busca mais inquietar do que necessariamente apontar para novos rumos. Como o próprio Ellul (2009), sem muitos receios, apressa-se em responder (Ellul, 2009, p. 274): “tal regressão é impensável. Vamos continuar obedecendo à regra técnica do primado dos meios, quer dizer que aceitamos o aumento dos problemas".

A convicção com que Ellul (2009) responde às questões postas por Elgozy reside no fato de que, no momento, há uma convicção profunda dos países centrais que é - na perspectiva de Jacques Ellul (2009) - a tendência de transformar problemas sociais e humanos em problemas técnicos. De fato, como parece evidente, o progresso técnico resolve problemas e dificuldades. "Cada vez que os homens viram claramente um problema ou perigo, cada vez que eles decidiram responder, podemos dizer que o problema foi virtualmente resolvido" (Ellul, 2009, p. 275). Isso - além de responder ao próprio movimento da técnica - também se deve em função de uma convicção fundamental dos países desenvolvidos que remete à noção de que tudo pode ser "reduzido a um problema técnico" (Ellul, 2009). Nesse caso, diante de um problema social, político, humano ou econômico, há uma tendência, conforme depreende Ellul (2009), a analisá-lo e transformá-lo em "um problema técnico (ou um conjunto de problemas técnicos)".

Assim, uma vez que o problema social, político, humano ou econômico é reduzido a uma questão técnica, aquilo que se apresenta como o caminho adequado - como a escolha perfeita - para a solução é a dimensão técnica. Ellul (2009) nota, contudo, que, embora tenha a aparência de escolha perfeita, é necessário considerar que essas escolhas lidam com um grande volume de dados, o que as torna, tanto na forma como se apresenta, quanto nos caminhos que são trilhados, cada vez mais confusas. Ellul apresenta três exemplos que nos ajudam a compreender melhor aquilo 
que ele propõe nessa segunda fórmula, que envolve a ênfase de que o progresso técnico - ao resolver determinados problemas - cria outros mais complexos, "gigantescos" e "imprevisíveis".

Os limites de espaço e os objetivos deste artigo não permitem que nos concentremos nos três exemplos descritos pelo autor. Consideramos relevante, em todo caso, assinalar um dos casos mencionados. Nas palavras do autor (2009, p. 277): "um segundo exemplo dessa lei de crescimento dos problemas com o crescimento das técnicas, nos é apresentada com o questionamento do mundo natural no qual o homem foi chamado a viver". O exemplo em tela, conforme se depreende da citação anterior, envolve o problema ecológico, ou seja, a questão da poluição do meio ambiente, os problemas com os ciclos naturais, a possível escassez dos recursos naturais, a poluição das águas, a contaminação dos solos etc. Ora, "esses fatos são, hoje, indiscutíveis, apesar das oposições. E tudo isso é o resultado do crescimento desenfreado e da aplicação ilimitada das técnicas" (Ellul, 2009, p. 278). Não são poucos os movimentos e reflexões que se voltam para esse paradoxo; apenas para lembrar que, no momento, é "mais difícil deixar o Mar Mediterrâneo integralmente limpo do que fazer voar um avião" (Ellul, 2009, p. 278).

Passamos a terceira fórmula em que Ellul (2009) busca suporte para a sua caracterização de ambivalência das técnicas. Também nesse caso, cremos que é possível encontrar uma síntese do pensamento do autor sobre ela em uma reflexão que Ellul (2009) descreve do texto de B. de Jouvenel (1968), quando este último enfatiza que "deterioramos o nosso meio ambiente não como indivíduos brutos", mas quando agimos em nome de uma função útil, com ações que consideramos racionais. Além disso, para o debate sobre essa terceira fórmula - "os efeitos nefastos do progresso técnico são inseparáveis dos efeitos benéficos", Ellul (2009) encontra 
suporte no princípio da entropia da ação, conforme desenvolvido por Edgar Morin (1981).

Em conformidade com Ellul (2009), o princípio da entropia da ação de Edgar Morin (1981) envolve a condição de que o sentido originário da ação tende a ser desviado e dissolvido no "jogo das inter-retroações”. A esse respeito escreve Ellul (2009, p. 289): "toda ação entra de modo aleatório em um jogo múltiplo e complexo de inter-retroação, onde a ação não tem o controle e, muitas vezes, não suspeita de nada" (Ellul, 2009, p. 289). O teólogo e sociólogo da tecnologia não desconhece que Edgar Morin (1981) não aplica explicitamente o seu conceito à ação técnica, porém Ellul (2009) adverte que, embora isso não se evidencie, não é inadequada essa associação, visto que as ações relevantes na nossa sociedade envolvem as ações técnicas.

Ainda sobre a terceira fórmula, "os efeitos nefastos do progresso técnico são inseparáveis dos efeitos benéficos", é necessário compreender nos termos postos por Ellul sobre a ambivalência das técnicas - que o próprio "coração" do sistema técnico produz de modo inseparável os efeitos bons e nefastos. Antes já questionamos e consideramos equivocada, com base em Ellul (2009), a suposta separação entre os efeitos bons e perversos da técnica, ou, ainda como alguns propagam, o pressuposto de que tudo se reduz à questão de como se usa a técnica.

Além dos argumentos apresentados em outra parte deste texto sobre as dificuldades em efetuar essa separação, também é preciso acrescentar que propor tal situação é partir do pressuposto que as técnicas não se “comunicam" com os seres humanos, e, além disso, acreditar que há uma coletividade de seres humanos sábios, virtuosos, os quais controlam seus desejos, instintos etc. Como escreve Ellul (2009, p. 284): “até aqui, a experiência mostra que o crescimento dos poderes técnicos não conduziu o 
homem à virtude. Dizer então que 'é suficiente saber fazer um bom uso', é a mesma coisa que não dizer nada".

No caso dessa terceira fórmula, cremos que também é útil recorrermos aos exemplos evidenciados pelo sociólogo da tecnologia no seu texto. Embora seja um exemplo simples, ele ilustra de forma adequada as posições do autor. A referência do autor é a estrada transamazônica que busca unir a costa até a fronteira peruana. São $3000 \mathrm{~km}$ no meio da floresta; uma "obra técnica gigantesca", mas, ao mesmo tempo, expõe "ao perigo todas as populações indígenas da Amazônia" (Ellul, 2009, p. 288). O exemplo anterior também mostra não só a existência dos efeitos, mas que os mesmos não se direcionam, necessariamente, no mesmo sentido.

Outro exemplo interessante posto pelo autor para ilustrar essa fórmula é a "poluição provocada pela luta contra a poluição". Como identifica o autor, os procedimentos de purificação do ar, especialmente nos Estados Unidos, mostram-se importantes em relação a poluição de fumaças.

Infelizmente, os gazes emitidos não evacuam as partículas sólidas, de modo que os diversos óxidos de azoto e enxofre podem combinar-se livremente com a água da atmosfera, formando ácido de azoto e de enxofre, o que a presença das partículas sólidas tinha, até agora, impedido. (ELLUL, 2009, p. 288)

Nos últimos anos, em diferentes partes, é comum a existência de chuvas ácidas, tão “ácidas quanto suco de limão” (Ellul, 2009).

Abordamos, finalmente, a quarta fórmula apresentada por Jacques Ellul (2009) com vistas à caracterização da ambivalência das técnicas. Essa quarta fórmula indica que "todo progresso técnico compreende um grande número de efeitos imprevisíveis". Seja no momento da invenção, seja na 
fase dos efeitos, a imprevisibilidade é, nesse caso, uma das características essenciais do progresso técnico e das técnicas (Ellul, 2009). No texto $A$ Ambivalência das Técnicas, Ellul (2009) mapeia três tipos de efeitos. Há os efeitos desejados, os efeitos previsíveis e, por fim, os efeitos imprevisíveis. Também nesse caso, os exemplos expostos pelo autor nos permite compreender melhor os termos da fórmula.

A ação de "furar um poço" é tomada pelo autor como forma de ilustrar os efeitos desejáveis. Assim, quando cientistas se concentram em pesquisar um problema técnico, há a busca de resultados específicos: como “furar um poço de 3.000 metros de profundidade para atingir uma jazida de petróleo?" (Ellul, 2009). Diante dessa questão e, enquanto esforço de busca, é provável que as técnicas existentes - e também outras a serem inventadas - sejam utilizadas. Isso é o que o autor denomina de efeitos desejados. Nas suas palavras (Ellul, 2009, p. 290): “esperam certo número de resultados e os obtêm. A técnica é bastante segura, ela dá os efeitos esperados [...], podemos estar seguros que o progresso técnico eliminará as zonas de incerteza em cada domínio" (Ellul, 2009, p. 290).

Para além dos efeitos desejados, há aqueles que não são procurados, mas são esperados. Podem ser considerados efeitos previsíveis. Uma intervenção cirúrgica pode tratar uma enfermidade, às vezes mais grave, e isso normalmente é justificativa para tal ação, mas não é incomum, como resultado, um conjunto de outras enfermidades menores (Ellul, 2009). "Evidentemente, trata-se de uma enfermidade penosa por outra mais leve, ou uma enfermidade que ameace a totalidade do ser, por outra que está localizada" (Ellul, 2009, p. 290). Por fim, além desses, há outros tipos de efeitos, quais sejam, os imprevisíveis, os quais, para o autor, são de dois tipos. Embora possa parecer estranho, há os efeitos imprevisíveis esperados e os imprevisíveis inesperados. 
No que concerne aos efeitos "imprevisíveis esperados", o autor aponta para o fato de que é possível "pressentir a possibilidade de que ele venha acontecer", porém temos limitações que não nos permitem garantia de que de fato poderá acontecer ou, mesmo, como irá ocorrer. Assim, por exemplo, é possível pressentir que haverá efeitos no comportamento e nas relações dos seres humanos em função destes passarem a ter uma existência confinada em "unidades habitacionais constituída de blocos", mas não temos condições, ainda, de prever com relativa segurança quais serão esses efeitos, sejam de ordem psicológica ou sociológica. Como escreve Ellul (2009, p. 291): “o homem vivendo na imensa unidade habitacional se transforma, mas no quê, e como, somos ainda incapazes de prever exatamente".

Tecemos, ainda, breve comentário sobre os efeitos "imprevisíveis inesperados". Sobre isso, os próprios exemplos descritos por Ellul (2009) são suficientes. Como menciona Ellul (2009), as culturas do algodão e do milho, aparentemente, consistiam em um grande progresso. Parecia não haver nada de mais a destruição de florestas para o cultivo de tais plantações, porém não demorou muito para se perceber que o "grande progresso" resultou em algo totalmente inesperado. Como escreve Ellul (2009, p. 291), “não podíamos saber que a ligação orgânica do húmus do solo é destruída pelas raízes do milho e do algodão". O fato, contudo, é que após determinado período de cultivo desses vegetais as terras se transformam em pó.

Finalizamos, assim, essa releitura do texto $A$ ambivalência das técnicas de Jacques Ellul. Após descrição e análise do seu conceito, bem como as fórmulas que apresenta para delimitação do mesmo, compreendemos que é possível ressaltar algumas contribuições para pensarmos o problema da naturalização da escola delineado no primeiro 
tópico e, em consequência, a crise da escola a partir da noção de ambivalência da tecnologia da escola. No próximo tópico, enquanto considerações finais, pretendemos destacar algumas notas sobre isso. Aliás, como o próprio termo utilizado na introdução demarca, não é nosso foco uma apresentação exaustiva da questão, mas apenas levantar elementos introdutórios.

\section{Considerações finais}

Neste artigo, propomos abordar o problema da naturalização da tecnologia da escola. Há certo tempo que a instituição escolar moderna é alvo de diversas análises e enfoques críticos, os quais, de um modo geral, não focam no instrumento em si mesmo, ou seja, na escola enquanto tecnologia. Normalmente, a preocupação com a escola nos últimos tempos emerge em um contexto que envolve questões mais amplas, sejam elas sociais, econômicas, políticas etc. Compreendemos a importância desse tipo de análise, porém, neste texto, ao partimos do pressuposto de que é possível focar a própria tecnologia, o instrumento em si, temos como meta, em fase inicial e exploratória, propor a noção de ambivalência da tecnologia de Jacques Ellul como alternativa para problematizar a escola e as formas de pensá-la enquanto tecnologia hegemônica do educativo.

Nesse contexto, procuramos, assim, aduzir elementos teóricos para pôr em evidência a face oculta da escola, em contraponto ao discurso mitológico de escola como algo a serviço do progresso da humanidade. $\mathrm{Na}$ primeira parte do texto, efetuamos a caracterização do problema da naturalização da tecnologia da escola o qual se relaciona, inclusive, ao problema mais amplo da crise de sentido e de legitimidade da escola enquanto tecnologia hegemônica do educativo na sociedade moderna. $\mathrm{Na}$ segunda parte do artigo, procedemos à releitura de um texto central no 
pensamento do teólogo e sociólogo da tecnologia Jacques Ellul no que concerne a sua noção de ambivalência das técnicas.

Nessas considerações finais, assinalamos, de antemão, que a aproximação ao pensamento de Jacques Ellul aponta para elementos teóricos que demarcam o caráter histórico, não natural, não eterno de uma dada tecnologia; no caso do problema delineado neste texto, da tecnologia da escola. Da mesma forma, a releitura do texto $A$ ambivalência das técnicas delineia a urgência de abordarmos, cada vez mais, as faces não reveladas e ambivalentes da escola, como também a esse respeito escreve Cuesta (2004).

Com apoio em Ellul (2009), somos levados a perceber que pensar a escola enquanto tecnologia ambivalente talvez ajude a superar a crise de sentido e legitimidade da tecnologia da escola. Não estamos, de fato, em contexto não permeável à influência dessa tecnologia. Isso impõe limites ao nosso repensar da escola, implica participar de um universo de disputas. Como demarca Ellul (2009), as tecnologias - e nesse caso também a tecnologia da escola - se "comunicam" com os seres humanos. Assim, talvez diante da tecnologia da escola, a questão a se colocar, cada vez mais, não é o que fazemos com a escola, mas o que a escola faz conosco, o que nos tornamos enquanto consumidores da escola.

Consideramos, ainda, que o foco no texto de Ellul (2009) $A$ ambivalência das técnicas delineia aspectos que necessitam, em outros momentos, de maiores aprofundamentos. Em todo caso, pensar a escola enquanto tecnologia ambivalente significa perceber que não podemos pensar apenas a questão do uso da escola, os efeitos bons e perversos dela. A escola enquanto tecnologia implica numa mistura complexa de elementos positivos e negativos; enquanto tecnologia, ela possui duas orientações "precisas, com 
valores opostos". Caso pensemos a escola enquanto tecnologia, há pouca margem para a crença na sua neutralidade.

A partir de Ellul (2009), somos levados a perceber que a escola, enquanto tecnologia hegemônica do educativo, traz valores importantes, porém destrói outros valores, os quais temos dificuldade em saber se são mais ou menos importantes. A ampliação da lógica escolar para as diversas modalidades de práticas pedagógicas cobram um preço. Ao mesmo tempo que constrói algo, necessitamos a clareza de que também algo estar a ser desvalorizado, a ser destruído. Mesmo ciente, em conjunto com Ellul (2009), que não é nada fácil estabelecer uma relação de valor-valor entre criação-destruição, visto que são fenômenos com medidas e naturezas diferenciadas. Ao analisarmos a sua ambivalência, a tecnologia da escola resolve problemas, mas suscita outros mais, os quais clamam por nossa atenção. Aliás, conforme vimos, nem sempre os efeitos de uma tecnologia são apenas os desejados, há também os previstos e os imprevisíveis.

Em síntese, consideramos importante ressaltar a possibilidade de pensarmos a escola enquanto tecnologia em si, tecnologia ambivalente, que carrega dentro de si, independentemente do seu uso, duas orientações bem delimitadas, porém opostas. Os seus efeitos não são apenas uma questão de uso. Em um mundo em que tendemos a transformar os problemas humanos, inclusive os problemas educacionais, em problemas técnicos, problematizar a escola enquanto tecnologia hegemônica do educativo com base nas contribuições da filosofia e da sociologia da tecnologia torna-se uma tarefa por demais premente.

Por fim, consideramos conveniente tecer comentários sobre a possibilidade de utilizar ou não a noção de escola enquanto tecnologia. De fato, embora o movimento de crítica da instituição escolar possua certo tempo, a análise da escola enquanto tecnologia em si, o foco na estrutura da 
escola, não mostra a mesma aceitação entre os que se dedicam ao tema. Até que ponto podemos tratar a escola enquanto tecnologia, enquanto artefato? Em outro texto, nos dedicamos a esse problema de maneira mais acurada a partir dos escritos de Ivan Illich. Neste artigo, contudo, queremos assinalar que é difícil abordar fenômenos complexos e sociais sem certo nível de substantivação. Não é absurdo pensar que a própria noção de sociedade em Marx remete a determinada substantivação do conceito (Vieira Pinto, 2005).

Reconhecemos que há sempre o risco de simplificação e negação da complexidade do todo social na imagem da escola enquanto tecnologia, enquanto artefato social. Porém, Cuesta (2015) - ao se dedicar à noção de escola enquanto tecnologia e aos riscos que ela comporta - assinala que não é somente a noção de escola enquanto tecnologia, mas toda e qualquer imagem do social está eivada da possibilidade de reducionismos. Em conformidade com Cuesta (2015), concordamos, contudo, que há nessa forma de analisar a questão social a ideia de sistema e totalidade social. Além disso, como escreve o autor (2015, p. 62), "ha de recordarse aquí que su empleo connota el carácter histórico de cualquier institución social en tanto en cuanto arte factus es siempre obra humana y, como tal, resulta algo no natural, contingente".

Com isso, também em suporte em Cuesta (2015), compreendemos que a escola enquanto instrumento, enquanto tecnologia, nesse caso, é diferente da escolarização, que é um processo social e educativo, que se efetiva em uma sociedade capitalista, enquanto organização e modelo econômico. Embora estejam entrelaçados, do ponto de vista teóricometodológico, compreendemos ser possível pensá-los de forma mais específica, ciente dos limites que isso implica. Em suma, e para concluir, a noção da escola enquanto tecnologia remete à ideia de que ela não é um processo natural, como muitos acreditam, mas obra dos seres humanos. Isso 
demarca o caráter histórico, contingente e ambivalente da escola, uma tecnologia educativa hegemônica que se apresenta como caminho entre outras alternativas possíveis. Também nesse caso somos levados a pensar que há certos pressupostos, certas condições que conformam e delimitam o "raio de ação da escola" (Cuesta, 2015).

Além disso, as metáforas e similares podem revelar algo que, dificilmente, se revelaria de outra forma (Cuesta, 2015). Alguns autores clássicos, tais como Platão, por exemplo, mostraram a riqueza de se apresentar determinadas questões complexas com suporte aos mitos, alegorias e similares. Nesse caso, também compreendemos que a noção de escola enquanto tecnologia, tomada como uma forma de alegoria em relação à escola poderá ser extremamente útil para se pensar os limites e possibilidades dessa instituição nas sociedades modernas, especialmente se ampliarmos o diálogo com a sociologia da tecnologia e filosofia da tecnologia.

\section{Referências}

CANÁRIO, Rui. A Escola tem Futuro? Das promessas às incertezas. Porto Alegre/RS: Artmed Editora S.A., 2006.

. A escola e as 'dificuldades de aprendizagem'. Psic. da Educação, São Paulo, número 21, p. 33-51, 2005.

. Escolas: elogio da diversidade. Revista Noesis, Portugal, número 73, p.

26-31, abril/junho de 2008.

COMENIUS, João Amós. A Didática Magna. São Paulo: Martins Fontes, 2006 CUESTA, Raimundo. La escolarización de masas: un sospechoso y 'feliz' consenso transcultural. Cuadernos de Pedagogía, Espanha, número 334, p. 81-85, abril de 2004. 
. La escuela y el huracán del progreso. ¿Por qué todavía hoy es necesaria una crítica histórica de la escolarización de masas? In $\approx$ daga, Espanha, número 4, p. 53-94, 2006.

- Paradojas de la escuela en la era del capitalismo: carta a mis queridos críticos.

Disponível em:

$<\underline{\text { http://www.nebraskaria.es/Nebraskaria/Trabajos y publicaciones files/Co }}$ njuntoresen $\%$ CC $\% 83 a \% 20$ Felices.pdf $>$. Acesso em 10 de fevereiro de 2015. et all. Dossier Educación. Separata de la Revista de Andorra, Andorra, número 11, p. 7-110, 2011.

ELGOZY, Georges. O desordenador: o perigo informático. Lisboa: Arcádia, 1976.

ELLUL, Jacques. A ambivalência das técnicas. In: Anais do I Seminário Brasileiro sobre o Pensamento de Jacques Ellul. Araraquara: Universidade Estadual Paulista, Faculdade de Ciência e Letras, 2009. Pg. 259-294. - A Técnica e o Desafio do Século. Rio de Janeiro: Paz e Terra, 1968.

FEENBERG, Andrew. Questioning Technology. 3. ed. London and New York: Routeledge - Taylor \& Francis Group, 2001.

ILLICH, Ivan. Obras reunidas. Vol. I e II. México: FCE, 2006.

LIMA, Licínio C. Escolarizando para uma educação crítica: a reinvenção das escolas como organizações democráticas. In: TORRES, Carlos Alberto \& TEODORO, António. Educação Crítica e Utopia: perspectivas para o Século XXI. Edições Afrontamento, 2005. Pg. 19-31

MARCUSE, Herbert. A ideologia da Sociedade Industrial: o homem unidimensional. Rio de Janeiro: Zahar Editores, 1973.

MITCHAM, Carl; HOINACKI, Lee. The Challenges of Ivan Illich: a collective reflection. New York: State University of New York Press, 2002.

MONTERO, Julio Mateos. Problemas y apuntes para una historia crítica de la escolarización. Avances em Supervision Educativa, Espanha, número 18, p. 1-23, 2013. 
MORIN, Edgar. Pour sortir du XXe Siècle. Paris: F. Nathan, 1984.

PINEAU, Pablo. ¿Por qué triunfó la escuela? o la modernidad dijo: "Esto es educación", y la escuela respondió: "Yo me ocupo". In: PINEAU, Pablo; DUSSEL, Inés; CARUSO, Marcelo. La Escuela como máquina de educar: tres escritos sobre un proyeto de la modernidad. Buenos Aires, Paidós, 2001. La escuela en el paisaje moderno. Consideraciones sobre el proceso de escolarización. Disponível em:

$<\underline{\text { http://www.projetoprogredir.com.br/images/bibliografia-definitiva/01-02- }}$ 13-biblio/posmodernidad-y-la-globalizacion-de-marinis/raquel-soto/masbibliografia/pineau-la-escuela-en-el-paisaje-moderno.pdf $>$. Acesso em $10 \mathrm{de}$ fevereiro 2015.

PINTO, Álvaro Vieira. O conceito de Tecnologia. Rio de Janeiro: Contraponto, 2005. $2 \mathrm{v}$.

POMBO, Olga. O insuportável brilho da escola. Disponível em: <www.educ.fc.ul.pt/docentes/opombo/investigacao/brilhoescola.pdf $>$. Acesso em 05 de janeiro de 2015.

STUCHUL, Dana Lynn. Schooling as ritual and as technology: explorations in the social thought of Ivan Illich. 1999. 198f. Tese (Doctor of Philosophy) College of Education, The Pennsylvania State University, USA, 1999. 